\title{
Accessing and assessing appropriate widening participation data: an exploration of how data are used and by whom
}

\author{
Natalie Holland, Ann-Marie Houghton, Jo Armstrong and Claire Mashiter
}

Department of Educational Research, Lancaster University, Lancaster, UK

\begin{abstract}
When attempting to use data to inform practice and policy, the availability, accuracy and relevance of that data are paramount. This article maps the range of users interested in data relating to the UK ${ }^{1}$ widening participation (WP) agenda. It explores some challenges associated with identifying, defining, obtaining and using data to inform decisions about targeting and monitoring WP initiatives associated with student access, achievement and progression. It considers the pragmatic and strategic response by different users of institutional WP data within the UK. We use examples from previous institutional and commissioned WP research and evaluations undertaken over the past decade to illustrate some of the tensions concerning the access and assessment of WP data. We argue that whilst the increasing interest in WP participation data and evaluative feedback is commendable, attempts to establish a causal link between WP activity and changes in student awareness, aspiration, access and achievement are not straightforward. The diversity of producers, uses and users of WP data working in different sectors and institutions produces many challenges. The paper concludes with suggestions on ways data could be improved.
\end{abstract}

\section{Key words:}

Widening participation, targeting, monitoring, evaluation, data

\section{Introduction}

This paper addresses challenges regarding use of widening participation (WP) data in a context where assessments of funding impact and increased interest in using data to evaluate WP activity have become a priority. Calls for evidence of effective monitoring and evaluation to confirm appropriate targeting and prioritising of resources proliferate. For example, a recent Business Innovation and Skills (BIS) White Paper emphasised that higher education institutions (HEIs) have a 'Transparency Duty' to provide relevant data (BIS 2016a, 39). However, there seems to be a lack of recognition regarding the problems confronting practitioners attempting to access, collect and use the data. The aim here is to bring these challenges to the forefront for the purposes of assisting users and highlighting priority areas for future changes.

The paper begins with a review of three contextual factors. Firstly, policy interest in the use of WP data to identify differences in higher education (HE) participation according to individual equality characteristics (e.g. socio-economic status, location and previous educational experience of students and their family). Secondly, the types of data collected at each stage of the student lifecycle and, thirdly, consideration of the multiple users of WP data. These factors together provide the basis for 
discussing data-related challenges concerning policy change, access and collection as well as the diverse uses and users of WP data. The paper concludes by offering practical suggestions for future research regarding the access, assessment and dissemination of WP data.

\section{Context}

This section is made up of three sub-sections: wider policy influence, the types of data col- lected across the student lifecycle and current strategic and operational uses of WP data. We begin by reviewing UK HE policy documents that reflect the changing student profile.

\section{Policy interest and influence}

At the time of the Robbins Report (1963), only one in eighteen young people entered HE. Thirty years later, in the next major review of UK HE, the Dearing Report noted that there was nearly one in three (NICHE 1997, 3.9). This growth in the student population was accompanied by increased attention regarding the profile of students participating in HE. Recommendations 2 and 7 of the Dearing Report directly referred to use of data. Firstly, to incentivise HEl to 'demonstrate a commitment to widening participation, and have in place a participation strategy, a mechanism for monitoring progress' and reviewing achievement (recommendation 2). Secondly, Dearing called for the 'creation of a framework for data about lifelong learning, using a unique student record number' (recommendation 7), which as we discuss later, continues to provide a challenge for track- ing students from school through to HE. Although nearly twenty years ago, the Dearing Report provides a policy baseline for WP data, by signalling the importance of considering the student profile in more nuanced ways. Two commissioned reports provided detailed analysis of participation rates for 'ethnic minorities, women and alternative students' (Coffield and Vignoles 1997) and students from lower socio-economic groups and students with disabilities (Robertson and Hilman 1997). Other countries, including Australia with their Bradley Review (Australian Government, 2009), have undertaken similar reviews of the student profile and used their analysis to set targets to widen participation according to national priorities.

During the past twenty years, legislation based on research and analysis of the available data have influenced the student groups identified as a priority for targeted activity on the basis of their underrepresentation in HE. Measuring progress is not straightforward in part because of changes over time regarding which indicator to use and because for some categories of student there are a number of possible indicators. For instance, disability and social class are two categories where indicators have changed which, as we discuss later, can present challenges for students and institutions.

The availability, accuracy and relevance of data that may be used to measure progress and potentially provide a means of comparison is important particularly in view of its application in the targets associated with HEl access agreements. Currently in England, HEls wishing to charge $f 9000$ fees must produce an institutional access agreement that includes evidence of progress against institutionally set targets relating to WP recruitment, retention and progression. The Office for Fair Access, OFFA (2016), which monitors progress, notes the diversity amongst the targets set and the difficulty this creates in making direct comparisons. Nevertheless, targets appear to reflect both the wider sector influences communicated via the Higher Education Funding Council for England's (HEFCE) gui- dance and WP priorities of the HEl. For example, in Lancaster University's first access agreement (2006-2007) targets related to disabled students, minority ethnic students, students 
from National Statistics Socio-Economic Classification (NS-SEC) groups 4-7, state schools and mature students, with information drawn from internal data. This changed in 2011 with a decision set targets based on annual HEFCE WP performance indicators in order to:

- $\quad$ reflect national priorities for the recruitment of groups currently underrepresented in HE;

- $\quad$ provide a reliable and independent source of evidence regarding the University's progress in widening access;

- $\quad$ enable effective benchmarking to be carried out against the HE sector as a whole and/or against specific institutions or groups of institutions. (Lancaster University Access Agreement 2012-13, 7)

Since then, the targets have included the percentage of young degree entrants recruited from state schools or colleges, NS-SEC 4-7, low participation neighbourhoods and, for retention purposes, the percentage from low participation neighbourhoods no longer in $\mathrm{HE}$ after first year of study. Analysis of six comparator HEls targets as reported in their access agreement reveals that while they all draw on WP performance indicators, there is considerable diversity regarding the specific indicators selected. This is made more difficult with subtle differences (e.g. whether all first degree or not). Future changes in the data used by the sector are likely as HEIs respond to HEFCE's decision to cease publication of NS-SEC from 2017 and with the implementation of proposals for data transparency outlined in the White Paper (BIS 2016a, 39). The influence of this fluctuating data land- scape will be discussed in relation to the challenges this poses to practitioners attempting to collect and use data.

OFFA guidance issued in 2016 signals changing priorities for the 2016-2017 access agreements to support the goal of social mobility and tackle other inequalities discussed in the White Paper (BIS 2016a) and recent guidance. According to the ministerial guidance to OFFA, there needs to be a commitment to basing decisions about WP on evaluation and evidence that:

depends first and foremost on having good data and using it effectively, and we look to you to champion the effective collection of reliable and relevant data and its effective use. We would like you to require more from institutions in the information they provide to you about how they use evaluation and reflective practice and the expertise they draw on to help them make their investment decision. (OFFA 2016, 5).

The subsequent strategic guidance together with other data-driven agenda relating to monitoring and evaluating the effectiveness of outreach activities via the Higher Education Access Tracker (HEAT), or the metrics still out for consultation for measuring teaching quality as part of the teaching excellence framework (TEF) (BIS 2016b), all place greater emphasis on the student life cycle including access, achievement and progression. Demonstrating 'impact' in monitoring and evaluation is also imperative. Before discussing the use and current challenges associated with WP data, we briefly outline key sources and stages of data collection and analysis.

\section{Types of data: stages of data collection and analysis}

There are four main stages of the student life cycle for collecting and analysing data: out- reach, admissions, success and progression. There are multiple possible sources of WP data and each source presents its own challenges with respect to accessing and assessing the appropriateness in a context of the myriad of users and uses within an $\mathrm{HEl}$ and across the sector. Gaining access to accurate data is notoriously difficult and hindered by the lack of consistency in data categories used 
over time discussed previously. For example, within the UK context, the absence of a unique learner number as well as commercial sensitivity and value of data held by the Universities and Colleges Admissions Service (UCAS) has in the past seriously hampered data sharing and limited how WP data were used to plan out- reach and monitor participation. Since starting this paper, there are already signs of greater openness with UCAS responding positively to the call for greater transparency (UCAS 2016). The White Paper proposals pertaining to greater transparency of data sharing also extend to HEls which are required to provide relevant data to enhance data sharing and enable greater scrutiny on the basis of value for money and support for social mobility (BIS 2016a, 39-40). Although it is premature and naive to suppose that the transparency duty will address the multiple data sharing challenges, it is an important milestone. Having provided the broad context for data collection, we now move on to discuss the sources and issues associated with each of the four stages, outreach, admission, success and progression data.

\section{Outreach data for targeting and tracking}

Sources of outreach data relate to students participating in activities prior to arrival at university. One of the challenges regarding school data has been the multiple sources and formats used to provide the data. In recent years, many have used the Ofsted Data Dash- board which was an interactive display of school profile information available for every school in the UK. However, Ofsted (2016) recently announced the closure of this resource, directing users to the recently created DfE school comparison tool which potentially offers a similar service (DfE 2016). Such changes bring both advantages and disadvantages; for instance, all previous data held by the DfE will now be available via the National Archives but with 'some technical limitations. Searching by postcode, school or town name, or parliamentary constituency is not possible, for example' (Gov.uk 2014).

The profile of actual pupils participating in the activity is gathered from the school or from pupils themselves answering questions on anonymous feedback questionnaires. Individual student-level data prior to $\mathrm{HE}$ enrolment are difficult to attain and the absence of a unique learner number that the student retains as they move from school through to $\mathrm{HE}$ is a long-standing frustration in the sector. Over time, various solutions have been explored, with varying degrees of success, and the current initiative gaining national funding support to bridge the continuity gap in the data is HEAT.

HEAT is a collaborative database which allows member HEls in England to track students from previous institutions through to their current university. The database was originally developed by an Aimhigher ${ }^{2}$ Partnership to support their monitoring and evaluation activities. In 2014, HEAT secured HEFCE funding to recruit new institutional members and thereby enhance the collective capacity of HEI members and the sector to track participants engaged in longitudinal outreach activities (see http://www.hefce. ac.uk/sas/heat/ ). The HEAT database holds the details of all the schools and colleges with which a university has worked to enable analysis of patterns in engagement. HEAT also stores information on the progression pathway of individual students based on past involvement in outreach activities. Opportunities to share data with other members exist, but currently data exchange depends on a localised agreement due to the commercial sensitivity of the information. Whilst the system offers a step forward, it is not ideal given that not all HEls subscribe and although sustainability of the project is high on the agenda, there is inevitably no guarantee of its longer term viability. It will be interesting to watch the extent of data sharing in the future, especially in response to increased calls for transparency and further investment in initiatives 
such as the National Collaborative Outreach Programme (http:// www.hefce.ac.uk/sas/ncop/) that will draw heavily on the use of data to identify and target outreach activities where HE participation is lower than would be expected given the GCSE attainment rates (HEFCE 2016).

\section{Admission data to support monitoring and funding allocation}

Admission data published by the Higher Education Statistics Agency (HESA) relate to students who become students at a specific HEI. Most applications to a UK HEI are made through UCAS which produces an end-of-cycle report on sector trends (UCAS 2016). The current process generates a large amount of data on individual applicants, some of which are available to the HEl at the point of admission, and some which may be purchased. Concerns exist regarding the reliability of some of these data which depends on what applicants enter, for example, disclosure of disability, number of unknowns especially for ethnicity and the general confusion regarding the type of school (Houghton, Holland, and Armstrong 2016). Another source of data collected during the admission process originates from Student Finance England (SfE) which relates to students' eligibility for a student loan and HEI bursary offered as part of an HEl's access agreement. For students in receipt of Disabled Students' Allowance (DSA), it will also determine the institutional disability premium. Given the recent decision to stop collecting NS-SEC data, it is likely that information on students' financial background will become more important. Challenges associated with gathering sensitive data such as household income are dis- cussed later.

\section{Success data to inform decision-making and institutional planning}

The key performance indicators (KPI) used to compare HEls with regard to student retention are the percentage of students no longer in HE after the first year of study and the number of students continuing. However, at an institutional level, the success of students whilst studying is monitored closely by HEls which have the potential to analyse dropout rates and degree classification across WP groups, academic departments, degree programmes at the same time as taking entry qualifications and participation in targeted initiatives into account. National Student Survey (NSS) scores at the level of a course represent an increasingly influential and controversial measure of success; they use a combination of existing data sources combined with student feedback on the quality of their HE experience. Additionally, HESA requires HEls to collect and return 200 items of data per student (ONS 2016). From a WP perspective, it is possible to analyse HESA data and NSS scores at institutional and departmental levels with respect to different groups of students.

\section{Progression data about students once they leave university}

From a WP perspective, emphasis on the student life cycle means there is heightened interest in the eventual outcomes of a student participating in HE. It is possible to gather data on students once they have left HE by using the Destinations of Leavers from Higher Education (DLHE) database. This DHLE database allows HEls to track students from admissions (and prior to university, if using HEAT) through to their graduate destination, enabling HEls to monitor WP groups' further study, employment destinations and salary. In common with data collected at other stages of the student life cycle, there are concerns regarding robust- ness; nevertheless, since DHLE is included in HEFCE's Key Information Set and used as a KPI reported on league tables, HEl interest has increased as has the visibility of graduate employability destination data in $\mathrm{HEI}$ marketing. 


\section{Current use of WP data}

In this third contextual section, we briefly map some of the current strategic and operational uses of WP data. Figure 1 shows strategic purposes and Figure 2 shows operational purposes representing some of the strategic and operational uses; each figure is then divided into four main groups of staff - governance and planning, HE academic departments, HE staff working in WP and outreach, and researchers. Each group collects, uses and disseminates WP data for external and internal reasons which are illustrated in the final column of each figure.

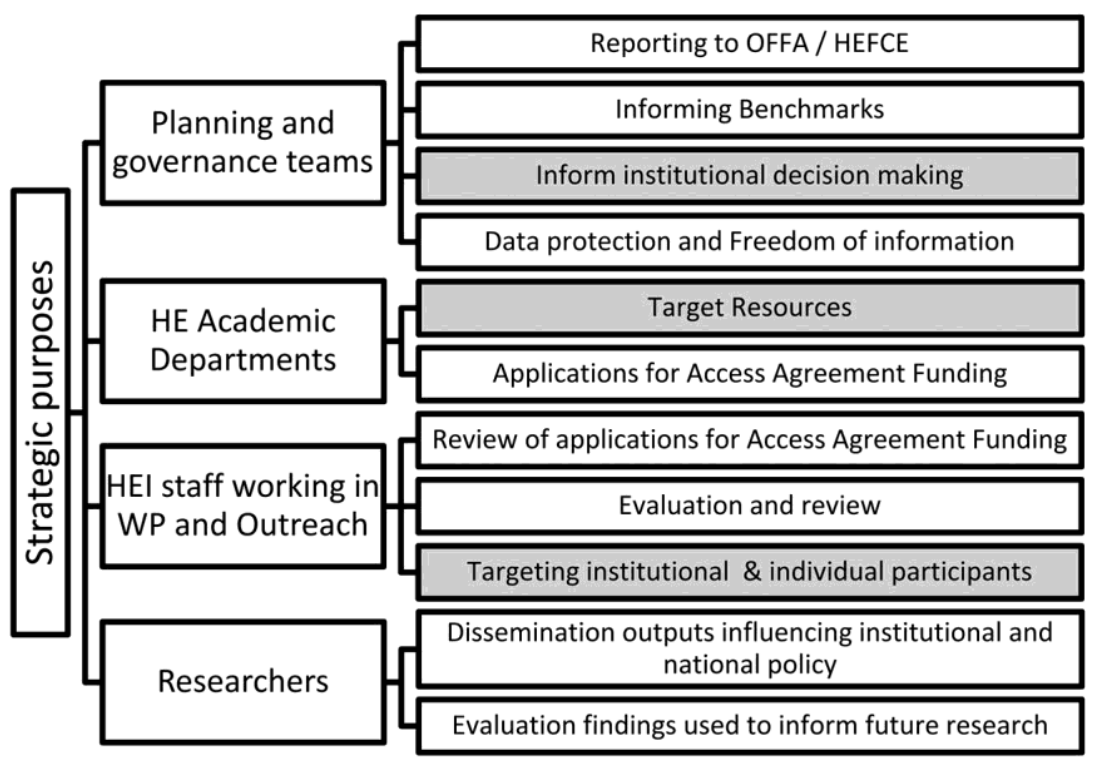

Figure 1. Strategic purposes.

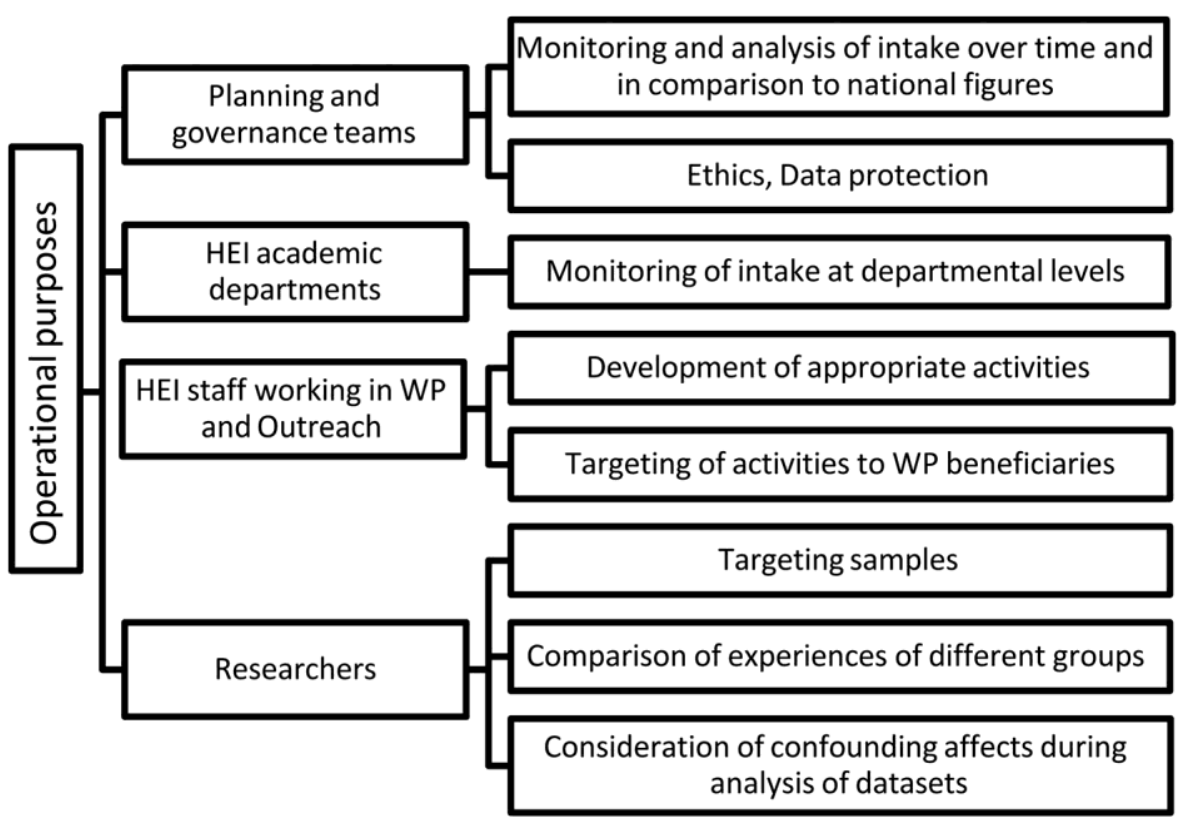

Figure 1. Operational purposes. 
The division between operational and strategic uses is not straightforward, and often data generated for and by one user group are deployed by other groups, not always with an appreciation of the underlying methodology or caveats that need to be considered. For instance, strategic purposes typically involve benchmarking and comparison either with other HEls or with sections within an organisation. HESA's (2010) exploration of the role of benchmarking together with the benefits and challenges referenced similar reviews by the European Centre for Strategic

Management of Universities (ESMU 2008). The benefits of benchmarking, and relevance, for the WP agenda included: self-assessment of performance; strengthening institutional identity; enabling the establishment of effective performance targets and accelerating the rate of improvement enabling change (see HESA 2010, 25). Closer consideration of data usage confirms that the primary remit of a particular user group will influence the challenges they may encounter; for instance, for planning and governance staff, changing definitions prevent longitudinal analysis. For WP practitioners asked to target a specific group, changes in the definitions both complicate and increase the time required to communicate the definitional changes to schools or colleges and check the eligibility of participants selected. Such changes also have implications for the robustness of targeting and once again highlight how constant change can lead to challenges in the practicalities of data collection.

External stakeholders such as OFFA, HEFCE, HEA, funders of research and organisations that champion increased participation or monitor aspects of the $\mathrm{HEl}$ experience of specific groups of students are deliberately absent from Figures 1 and 2 . The groups rep- resented within the figures are all internal within an institution, and by removing external stakeholders, we wanted to highlight the very different yet important and intricate role external stakeholders play in impacting on the internal uses of data.

For example, the Frank Buttle Trust helped to raise the profile of care leavers (www.buttleuk.org/areas-of-focus/quality-mark-for-care-leavers), a legacy reviewed in 2016 by Rawson on behalf of Action on Access. Meanwhile the Higher Education Academy's (HEA) teaching and learning remit focuses on retention and employability which encourages analysis of, and interest in, data relating to a specific phase of the student life cycle (see HEA Frameworks and Toolkits). There has also been an increased interest in surveys relating to teaching and learning as well as student engagement; for example, for undergraduates, the Student Academic Experience Survey (Neves and Hillman 2016) and for postgraduates, there are research and taught degree versions (Leman 2015) and looking more broadly, the HEA's UK Engagement Survey that builds on the international National Survey of Student Engagement. These surveys all promise evidence whereby HEls and others can compare their performance against other institutions. Whilst league tables have the potential to initiate institutional developments designed to enhance the student experience, the questions asked are not particularly helpful in generating potential solutions. Another area of concern relates to the way time-pressured staff may refer to only the headline figures in survey data, thereby neglecting important contextual detail that impacts interpretation and meaning of data.

External stakeholders are both providers and recipients of data and their priorities can and do influence the data collected by HEl. Through funding activities designed to enhance WP, OFFA expects HEls to set and monitor targets which will inform design and delivery of HEI WP outreach or post arrival retention activities. Although the absence of explicit externally defined targets may limit OFFA's capacity to monitor participation against national priorities, other mechanisms such as funding, benchmarks, guidance and commentary based on the analysis of access agreements signal 
the zeitgeist with respect to the type of data collected and how it is used. For example, the recent move away from including NS-SEC within the HEFCE performance indicators is likely to reduce the collection and use of these data, potentially leading to challenges when making comparisons over time. Furthermore, if we look at the uses of WP data within the strategic purposes section of the diagram, it is evident how many relate to external funders and governance, either directly such as

'Informing Benchmarks' and 'Applications for funding' or indirectly such as 'Evaluation and review' where the evaluation will ensure that activities target WP students to increase participation.

Consequently, those attempting to collect and use WP data are required to interpret and respond to the competing demands from both internal and external stakeholders.

\section{Challenges}

Whilst it is clear that there are a multitude of uses for, and users of, WP data within HEls, there are challenges associated with using data to inform decisions about targeting, monitoring and evaluating WP initiatives across the student life cycle. These challenges vary according to the different user groups but typically relate to policy changes and methodological considerations, issues of access to data and its collection. They include the reliability and robustness of data, ways it is disseminated and the different claims made based on those data. We mirror the previous context section, by considering three broad challenges that relate to: policy changes and their influence on disability, social class and gender data sets; issues concerning the access and collection of data and the third challenge data uses and users.

Based on the current political emphasis on the importance of evaluation of outreach (and our own institutional context as researchers and evaluators often work with WP staff on evaluation), our discussion focuses on issues facing two user groups, namely WP practitioners and staff involved in evaluation or research. We use observations from previous research and current evaluations to illustrate challenges relating to the out- reach and admission stages of the student life cycle. Relevant literature was sourced through standard search techniques including peer-reviewed papers, academic and practice-orientated publications ranging from policy papers and 'grey' literature.

\section{Policy change}

Policy change in WP has important implications for the target social groups and the ways categories are constructed. These shifts, while somewhat inevitable, present a challenge for users of data as illustrated in the next three sub-section discussing disability, social class and gender. The data sets chosen were selected because of their topicality in current UK policy agenda and connection with previous research; they are not exclusive. See, for example, a discussion of mature part-time students (Houghton and Holland 2016) and Stevenson's (2012) report on attainment of Black and minority ethnic students.

\section{Disability}

Despite HEFCE's reported success in widening access of disabled students with an increase from 16,700 new entrants in 2003-2004 to 51,300 in 2012-2013 (HEFCE 2015/14, 8), dis- abled students have featured as a priority group for widening access due to their relative low participation and concerns regarding students not in receipt of DSA. HEFCE have provided additional funding for HEls on a pro rata basis of weighted student full-time equivalents from the previous year in receipt of DSA (HEFCE, 2014/06, 25). HESA data on student numbers reflect recognition of the additional 
requirements and concerns about HEls' capacity to fulfil what became their legal obligations under the Disability Dis- crimination Acts (1995 and 2005), Special Educational Needs Disability Act (SENDA) 2001 and Equality Act 2010.

Although data are based on answers to the compulsory self-declaration disability ques- tion, part of the undergraduate application process administered by UCAS means students may choose not to disclose for a variety of reasons (HEFCE 2015). As well as policy drivers influencing institutional income, disclosure of disability carries a financial incentive for a student in terms of their potential entitlement to DSA.

Although policy drivers encourage both the institution and the individual student to ensure the data are accurate, there are inherent challenges. For an institution, these concern: capturing disclosure post arrival, identifying trends, monitoring progress and preserving anonymity for small groups of students. There are also challenges relating to the different terminology used in school - Special Educational Needs, and HE - disability (Houghton and Piggott 2008); and for the individual, decisions about identification with the disability label and subsequent disclosure still appear to be influenced by a fear of dis- crimination, especially for students with mental health difficulties (HEFCE 2015).

\section{Social class}

For social class, challenges concern issues of accessing the data and debates about the accuracy, relevance and robustness of the proxies used which include: parental occupation, household income and previous educational experience (see NS-SEC below). Interest in 'postcodes' as another proxy has grown since the availability of the participation of local areas (POLAR) groups, which show the proportion of 18-year-olds entering HE, based on local areas that are broken down into five groups, with 1 representing the lowest participation group (quintile) and 5 the highest. POLAR data were used to identify and compare regional differences during the Aimhigher era; more recently, HEFCE used it to identify 'cold spots' for prioritising the action of the National Networks of Collaborative Outreach (see http://www.hefce.ac.uk/sas/nnco/) and forthcoming National Collaborative Outreach Partnerships (see http://www.hefce.ac.uk/sas/ncop/ for initial call). Efforts by HEFCE to enhance the accuracy of this data source and support the sector in accessing data are evident with their introduction of the interactive map of young participation areas (see

http://www.hefce.ac.uk/analysis/yp/POLAR/). However, increased use of POLAR data is not without its problems. As Harrison et al. (2010) note, the reliability of using postcode data as a proxy for disadvantage in both rural and urban contexts has been questioned due to specificities and anomalies associated with particular locations.

\section{Gender}

Interest in gendered participation traditionally relates to specific disciplines and highlights concerns regarding under-representation of, for example, women in Science, Technology, Engineering and Mathematics (STEM). Initiatives such as Athena Swann heighten the relevance and importance of collecting gender data, as they require staff working in STEM subjects to carefully analyse the gender profile of their students and generate an action plan to influence future change. Although comparable concerns exist regarding the gender balance in other disciplines, there is often not the same structural or financial incentive to address different participation rates.

Tackling gender differences in participation is possible; however, as recent research pertaining to the WP of medical students suggests, monitoring data over time and holistically is essential to identify 
gradual changes in participation and ultimate progression. For instance, whilst $55.7 \%$ of female students enrolled to Medicine and Dentistry in 2013/14 (25,425 female, 20,245 male) (HESA 2013/14), the Selecting for Excellence report presents General Medical Council data showing $56 \%$ of doctors are male (MSC 2014, 17).

In summary, policy changes present some additional and recurring challenges to WP practitioners who use data for eligibility and monitoring purposes and researchers concerned with changes over time. The type of evidence used to measure WP status, the criteria used to define specific groups of students as well as which groups are identified as a priority are constantly evolving. Additionally, the differential treatment of some WP groups within certain disciplines due to the different incentives created by policy (e.g. girls in STEM) can influence patterns of participation. Awareness of policy influences at both a national and institutional level is therefore important but from a WP practitioner perspective, where posts are often fixed term or project funded, this knowledge may be limited. Finally, accuracy may be hindered by a lack of acknowledgement regarding the complexities in collecting some data (e.g. self-disclosure of a disability, especially a mental health condition).

\section{Accessing and collecting data}

The second challenge, which is a primary concern for WP practitioners, is how to access, collect and use data to target activities at eligible schools/colleges or individual participants and monitor effectiveness. The data fall into two broad categories: publicly available data aggregated at school level and individualised data available via a school or provided by the individual. The availability of school data regarding exam results, entitlement to free school meals (FSM), pupil premium/16-19 bursary, and catchment area means that it is often used as a proxy for educational disadvantage.

Gaining access to consistent school data is problematic and hindered by frequent changes to the format of data sources and tools such as the recent abolition of the Ofsted dashboard, all of which mean that effective targeting is difficult. Access to school data is only the first step since ensuring the eligibility of selected pupils is dependent on teachers having time and their willingness to use the designated criteria. Once pupils are selected, WP practitioners then need to monitor the effectiveness of their targeting and undertake tracking to support evaluation of their interventions. Depending on whether data are required for individuals or a group influences the practical and ethical issues that need considering. For example, greater granularity will support tracking but involves additional ethical and data protection considerations that become increasingly complex for collaborative projects.

In addition to these general practical challenges, there are questions of accuracy and specific problems associated with specific types of data. We now discuss three such issues relating to the outreach and admissions stages of the student lifecycle: category definitions (NS-SEC and parental occupation), changing definitions (institutional type) and sensitive data (personal finance).

\section{NS-SEC - a question of definition}

Attitudes towards NS-SEC vary. As Payne notes, 'although NS-SEC is preferred for its practical utility, the measurement of occupational groups remains problematic, indicating the continued need to improve the tools of class analysis' (Payne and Payne 2013, 3). The accuracy of NS-SEC data, like parents' previous educational experience, is limited due to the process of self-completion (Harrison et al. 2010; Hoare et al. 2011). Problems occur because the categories are open to interpretation 
and the guidance typically provided is inevitably brief. Such definitional challenges are widespread (see Lynch et al.'s (2015) study of admission data in Australia).

The practical challenges associated with gathering information for the purposes of assigning an NSSEC were highlighted during participant observation of research we con- ducted for Aimhigher Cumbria in 2010. Firstly, there was considerable suspicion and resistance from parents to providing the information, secondly, there was additional discomfort for those with limited literacy and, thirdly, even where support was offered, descriptions of parents' work or job titles made it difficult for WP practitioners to consistently assign to categories.

Mcmanus and McManus (2004) highlighted similar concerns regarding the reliability and validity of NS-SEC admission data supplied by UCAS. McManus describes the process where applicants record the job title of their parent (or, in the case of mature students, themselves or their partner) which UCAS uses to assign a social class. McManus argues that younger entrants are unlikely to understand either the subtleties or importance of accuracy, giving the example of the ambiguous term 'manager' (Mcmanus and McManus 2004).

Do et al. (2015) explain a further issue with how parental occupation data are collected at the point of application; they draw attention to the UCAS instruction asking non-school leavers to record their own or their partner's occupation rather than parental occupation. For many mature students, the question would make sense. However, Do et al. argue that, for some degree courses (e.g. medicine), where applicants apply directly after a first degree, data may be skewed. In such cases, applicants are officially mature, but recorded as a student, in a low-paid job or unemployed, thereby assigning them to a lower socio-economic group, suggesting experience of educational disadvantage when this may not be the case (Hoare et al. 2011).

\section{Institution type - complexity leading to confusion or manipulation}

Whilst acknowledging that not all state schools offer the same educational opportunities, the simple breakdown into state or independent schools is a common indicator. For the WP practitioner, schools are easy to identify and admissions data suggest that this is a reliable divide. However, it appears that when categories are broken down to become more nuanced, reliability is debatable. Whereas the type of school may have signalled educational experience in the past, the introduction of academies, specialist colleges, free and teaching schools, whilst offering diversity of opportunity, has increased the complexity of gathering these admission data. Recent research analysing 20142015 applicants to Lan- caster University Medical School revealed a considerable number of discrepancies regarding school type (Houghton, Holland, and Armstrong 2016). Use of this relatively small data set (1800) permitted identification and recoding of the erroneous categorisations. For example, sixth forms attached to a school were often recorded as Further Education (FE) colleges and independent schools as academies. Reasons for the inaccuracy are difficult to pinpoint and warrant further investigation. One explanation is genuine confusion over the status of an institution while another is the possibility applicants respond in a way they believe will enhance their opportunities. Given such concerns, caution is needed if school type is to be used as a proxy for either WP outreach targeting or as applicant con- textual data. Hoare et al.'s (2011) Bristol University case study offers further examples of how data pertaining to institutional type may be used during admissions, assuming of course it is accurate. 


\section{Financial information - a question of disclosure}

The disclosure of financial information is a complicated and sensitive issue. For the WP practitioner, a high percentage of FSM, pupil premium and 16-19 bursary recipients are common indicators used to select schools for involvement in WP activity. Yet, as noted above, the school profile does not necessarily correspond to individual pupils' profiles. However, assessing eligibility to participate in high-intensity activities raises practical and ethical challenges for practitioners. For instance, Aimhigher Cumbria used FSM, parental education and POLAR data to establish eligibility. But as knowledge of selection criteria increased, pupils (or their parents) sought to 'cheat the system' by completing application forms for a summer school place using information they believed would increase their chance of acceptance. Checking the accuracy of such applications was problematic and often came too late, with some teachers being complicit, objecting on principle to the use of specific selection criteria.

Disclosure of sensitive financial information is another consideration. Whilst pupils and their friends may be aware of their entitlement to FSM, they may not want to broad- cast this fact to others. Consequently, questions on evaluation forms, where others can see an individual's answers, may be problematic. Similarly, where the accompanying teacher is asked to provide personal details regarding a group of unfamiliar pupils, the information either remains incomplete or they ask pupils to disclose their status sometimes without an awareness of the associated ethical implications.

To determine entitlement to financial assistance at university, HEls either rely on students' disclosure in applications for tuition fee and maintenance loans or establish individual institutional practices for collecting financial data. There is no requirement for anyone who does not need or want a full maintenance or tuition fees loan to disclose financial information and some may be wary of disclosing information fearing it may impact on their entitlement to social support or interfere with their taxes. Decisions relating to dis- closure are complex. Previous research suggests differences in attitudes to debt according to ethnicity and religion (e.g. Connor et al. 2003; CHERI and London South Bank University 2005), meaning financial information may be disproportionately missing for certain ethnic or religious groups.

Connor et al. (2001) highlighted how Asian students are least likely to have borrowed from a bank or have an overdraft. Connor et al. (2003) further found that Indian and Chinese/Asian other students were less likely than other ethnic groups to have a student loan. Similarly, Callender and Kemp (2000) identified that some Muslim students hold different attitudes towards debt which incurs interest and Connor et al. (2003) found that Muslim students were the least likely to have a loan though only slightly less than Hindu or Sikh groups.

A recent review of the Lancaster University Medical School application process found that a high percentage of students and their families withheld information $(N=57,55 \%)$ and that this was more pronounced among certain ethnic groups. For example, 12 out of the 13 (92.3\%) students from an Asian-Pakistani background chose not to provide details of household income (Houghton, Holland, and Armstrong 2016). Numbers are too small to draw any definitive conclusions, though potential explanations include, for example, families' reluctance to engage with a loan system for cultural reasons, a lack of awareness regarding entitlement or uncertainty regarding the online registration process. Another possibility is that families are aware of information on the Student Finance England website stating 'You can apply for the Tuition Fee Loan and 65 per cent of the Maintenance Loan 
without having your household income looked at' (Student Finance England 2015) and elect to gain access to funding available to them without disclosing their financial income. Accessing sensitive data is inevitably a challenge and, once collected, it is important to assess the reliability of the data to inform the strength of the claims drawn as well as exploring reasons for missing data to influence awareness-raising activities and provision of information, advice and guidance.

Collection of WP data is therefore dependent on individual disclosure and should be considered carefully for accuracy given the potential for misunderstanding or manipulation.

\section{Data uses and users}

Thus far, we have focused on quantitative participant or student enrolment data that enable HEls to monitor the profile of participants in WP outreach activities or students applying and being admitted to study for their degree. The third challenge we explore concerns data uses and users.

HEFCE suggested four levels or stages of evaluation, monitoring, targeting, measurement of outcomes and assessment of value for money (HEFCE 2010, 3). In our discussion, we have focused on quantitative data relevant to the first two of the HEFCE stages, participant or student enrolment data that enable HEls to monitor the profile of participants in WP outreach activities or students applying and being admitted to study for their degree. A source of both quantitative and qualitative data is the evidence gathered by WP practitioners to evaluate their own practice and gain feedback from participants to enable them to measure outcomes. Feedback forms generally comprise quantitative data collected using closed questions, often designed by the practitioners themselves based on forms used in marketing and recruitment and sometimes informed by national guidance on building evaluation capacity (for example, Dent et al. 2014; HEFCE 2008/05). A review of feedback forms used for Lancaster University OFFA-funded projects (2014-15) revealed an anecdotally common situation in which there was considerable diversity in the focus and wording of questions. Whilst questions were relevant and appropriate, the lack of consistency prevented analysis at the institutional level; similar limitations exist at a national level for activities such as summer schools or mentoring. This difficulty can be addressed; for example, Lancaster University has centralised evaluation activity and introduced standardised questions to enhance consistency and aid comparison of feedback across different projects. Similarly, some National Networks for Collaborative Outreach are using a standard evaluation form. The HEAT consortium is also currently exploring use of generic questions derived from the Youth Cohort Study longitudinal survey (DfE 2011); whilst too early to assess the effectiveness of this approach, it clearly has potential.

Although outside the scope of this paper, there is also a growing interest in qualitative data gathered via focus groups, individual interviews with participants and staff responsible for delivery as well as a plethora of alternative and creative approaches such as photo elicitation or naturalistic data generated during activities. The next section draws together the issues regarding reporting and challenges associated with dissemination and making claims based on data.

\section{Reporting and dissemination}

We argue that whilst increasing interest in WP data and evaluative feedback is commend- able, attempts to use data to establish a causal link between WP activity and changes in student awareness, aspiration, access and achievement are not straightforward. Given the diversity of producers and users of WP data working in different sectors and institutions, one challenge relates 
to improving discussion and dissemination through acknowledging the diversity of audiences and producers, each serving different purposes. Concerns relating to dissemination include lack of rigour, transparency, visibility and usability all of which may render the conclusions drawn questionable. To be effective, these proposals need to be accompanied by appropriate recognition of the challenges facing WP practitioners collecting data as well as adequate resources to enable improvements.

The differing demands of internal and external stakeholders lead to additional demands on WP practitioner time. Furthermore, policy change has implications for the specific data to be collected which, in turn, makes longitudinal analysis difficult. Finally, the practical limitations when collecting WP data and the impact of this on its accuracy need to be taken into account when interpreting WP data. In our conclusion, we focus on ways in which WP practitioners and researchers can overcome these challenges.

\section{Conclusion}

This Special Issue focuses on innovative methods and theories in WP research; our contribution to this discussion has been one of exposing some of the challenges. Next, we offer ideas for how WP practitioners and researchers can overcome these challenges and together contribute to the development of WP theory based on innovative research.

A long-standing criticism of WP research and evaluation is the dominance of small- scale studies often lacking clear and rigorous research design and sufficient methodological detail to enable further scrutiny of the claims (Gorard et al. 2006). Although such criticism may be justified in reference to final articles or reports, it may be more a matter of space and time rather than any shortcomings in design and rigour of innovative methodologies. Further resources are required to build the capacity to prepare additional articles to disseminate novel methodologies that can be effective in researching the complexity of WP activities.

The recent trend to present data visually and in an 'engaging' manner (sometimes described as 'infographics') appears to address the need for greater transparency. However, this type of reporting inevitably has both advantages and disadvantages. Examples of effective use of visual representations of the data include the Social Mobility Index (2016) which displays data using a combination of easy-to-read graphs and maps. Importantly, with respect to transparency, the report provides a breakdown of the figures within additional tables and accompanying text. However, other attempts to visualise data may focus too much on the attractiveness of displays at the expense of providing the necessary level of detail for the reader to engage appropriately and actually use the data. For example, an absence of appropriately labelled graphs or information contained in tables can restrict comparisons between institutional and national figures. The inclusion of technical appendices and provision of data sets is vital; it represents good practice and allows readers to independently assess the rigour and transparency of data. Nevertheless, effective use is still dependent upon on the individual readers' capacity to appropriately interpret and evaluate the statistical approaches which may be limited. Collaboration between different users supports accurate reading of the data and helps to ensure that insights from practitioners are included in the resulting discussions.

A final hurdle in using data collected by others relates to its visibility, availability and accessibility. The time required to formally report and disseminate evidence is rarely avail- able even where data 
do exist. There are also several reasons why dissemination outside the institution may be restricted. For example, there may be resistance on the part of the staff responsible for gathering the data if their future funding depends upon the findings or it may be the case that there is simply a lack of capacity to draw conclusions in the midst of large amounts of data and insufficient experience in its analysis. We argue that until there is wider policy coherence with different stakeholders sharing the same goal, fragmentation and competing priorities are likely to jeopardise any real sustainable progress in the usability of standard data sets and the acknowledgement of more innovative data.

Arguably, the most pressing issues appear to concern the absence of a unique learner number recognised across different educational sectors and the limitations associated with the accuracy of different data sources resulting from a multiplicity of definitions, sensitivity around certain information and the reliability and relevance of claims based on the data. There are benefits in HEls adopting WP HEFCE performance indicators within their OFFA access agreements, but there remains considerable diversity that makes comparative analysis problematic. Given the diversity of users of WP data, the dominance of metrics based on numerical data is also a cause for concern. Such data are often valuable as a basis for further investigation, but greater attention to qualitative research (drawing on innovative methods outlined in this special issue) is required for a thorough assessment of the effective features of WP activity. Research needs to be able to explore the selection processes used by teachers to identify pupils for WP activity, families' understanding of these activities and the meanings attached to certain labels which ultimately affect disclosure and eligibility as well as the accuracy of the data themselves. Given the investment in WP activity across the student life cycle and the number of staff involved in delivering pro- jects, the benefits of sustained collaboration between different user groups and with external stakeholders should be explored ideally within a context where policies across sectors are coherent and complementary. Sadly, until there is wider policy coherence with different stakeholders sharing the same goal, fragmentation and competing priorities are likely to jeopardise any real sustainable progress.

\section{Notes}

1. Data requirements for England, Wales, Scotland, and N Ireland vary according to the complex remits of government and devolved administrations in the UK. Although the issues discussed in this paper predominantly relate to the English context, we argue, this does not detract from the central arguments presented regarding common and widely shared concerns relating to data collection and use by different users working within a HEI and the HE sector more broadly.

2. Aimhigher was a widening participation initiative funded by the former Department of Education and Skills working with the Higher Education Funding Council for England (HEFCE) between 2004 and 2011.

\section{Acknowledgements}

We would like to thank the reviewers for their useful observations and comments on the initial draft

\section{References}

Allen, L., Solomon, L., Storan, J. Thomas, L. (2005) Higher Education in the USA, Student fees, financial aid and access, Series Editor: Stuart, M. International Comparators of Widening Participation in Higher Education - Policy and Practice. Action on Access. 
Australian Government, (2009) Transforming Australia's Higher Education System (Bradley Report) http://planipolis.iiep.unesco.org/upload/Australia/Australia TransformingAusHi gherED.pdf

BIS - Department for Business Innovation and Science (2016a) Success as a Knowledge Economy: Teaching Excellence, Social Mobility and Student Choice BIS/16/265 (Cm 9258). https://www.gov.uk/government/uploads/system/uploads/attachment data/file/5 23546/bis16-265-success-as-a-knowledge-economy-web.pdf

BIS - Department for Business Innovation and Skills (2016b) Teaching Excellence Framework: Technical consultation for year two (May) https://www.gov.uk/government/uploads/system/uploads/attachment data/file/523340/bis16-262-teaching-excellence-framework-techcon.pdf

Callender, C. and Kemp, M. (2000) Changing Student Finances: Income, Expenditure and the Take-up of Student Loans Among Full- and Part-time Higher Education Students in 1998/9, Research Report 213. South Bank University: DfEE.

Centre for Higher Education Research and Information (CHERI) and London South Bank University (2005) Survey of higher education students' attitudes to debt and term-time working and their impact on attainment: A report to Universities UK and HEFCE. London: Universities UK. http://www.universitiesuk.ac.uk/highereducation/Documents/2005/TermTimeW ork.pdf

Coffield, F. and Vignoles, A. (1997) Widening Participation in higher education by ethnic minorities, women and alternative students. (Report 5 for National Committee of Inquiry into Higher Education). Available at: http://www.leeds.ac.uk/educol/ncihe/

Connor, H. and Dewson, S. with Tyers, C., Eccles, J., Regan, J. and Aston, J. (2001) Social class and higher education: Issues affecting decisions on participation by lower social class groups, Research Report 267. Institute for Employment Studies: DfEE.

Connor, H., Tyers, C., Davis, S., and Tackey, N. D. with Modood, T. (2003) Minority Ethnic Students in Higher Education: Interim Report. Research Report RR448.London: Department for Education and Skills. http://webarchive.nationalarchives.gov.uk/20130401151715/http://www.educati on.gov.uk/publications/eOrderingDownload/RR448.pdf

Dent, P., Garton, L., Hooley, T., Leonard, C., Marriott, J. and Moore, N. (2014) Higher education outreach to widen participation: Toolkits for practitioners, Higher Educational Academy. https://www.heacademy.ac.uk/resources/resource2322

DfE - Department for Education (2016) 2016 School and college performance tables: statement of intent (August 2016).

https://www.gov.uk/government/uploads/system/uploads/attachment data/file/543720/2016 School and college performance tables statement of intent.pdf.

DfE - Department for Education (2011) Youth cohort study and longitudinal study of young people: 2010. https://www.gov.uk/government/statistics/youth-cohort-study-and-longitudinal- studyof-young-people-in-england-the-activities-and-experiences-of-19-year- olds-2010

Do, P., Parry, J., Mathers, J and Richardson, M. (2006) "Monitoring the widening participation initiative for access to medical school: are present measures sufficient?". Medical Education, 40, pp. 750-758.

ESMU. (2008). "Benchmarking in European Higher Education: Findings of a Two-Year EU-Funded Project." European Centre for Strategic Management of Universities. http://media.ehea.info/file/Transparency/75/1/benchmarking report 1101 607751.pdf

Gorard, S., Smith, E. May, H. Thomas, L., Adnett, N. and Slack, K. (2006) Review of widening participation research: Addressing the barriers to participation in higher education. Report to 
HEFCE by the University of York, Higher Education Academy and Institute for Access Studies. http://dera.ioe.ac.uk/6204/1/barriers.pdf

Gov.uk (2014) Historical information. Available at: https://www.compare-schoolperformance.service.gov.uk/historical-information)

Harrison, N. and Hatt, S. (2010) "Disadvantaged learners': who are we targeting? Understanding the targeting of widening participation activity in the United Kingdom using geo-demographic data from Southwest England'. Higher Education Quarterly, 64, 1 pp. 65-88.

HEFCE (2008) Guidance for Aimhigher partnerships Updated for the 2008-2011 programme (2008/05) including evaluation capacity building 'toolkit'. http://www.lancaster.ac.uk/fass/events/capacitybuilding/index.php

HEFCE (2010) Widening participation strategic assessments: guidance on developing evaluative approaches to widening participation activities and commitments, (24/2010) http://www.hefce.ac.uk/media/hefce/content/pubs/2010/CL,242010/cl24 10a.pdf

HEFCE. (2014) Guide to Funding and Student Number Controls 2013-14 and 2014-15: How HEFCE Allocates Its Funds and Controls Student Numbers. http://www.hefce.ac.uk/pubs/vear/2014/201406/.

HEFCE (2015) Delivering opportunities for students and maximising their success: Evidence for policy and practice $2015-2020$ (2015/14) http://www.hefce.ac.uk/media/HEFCE,2014/Content/Pubs/2015/201514/HEFCE2015-14.pdf

HEFCE (2016) National collaborative outreach programme: Invitation to submit proposals for funding (2016/06) Available at: http://www.hefce.ac.uk/sas/ncop/

HESA (2010) Benchmarking to improve efficiency Status Report November 2010. Higher Education Statistics Agency.

https://www.hesa.ac.uk/dox/Benchmarking to improve efficiency Nov2010.pdf

HESA. (2013/14). Introduction-students 2013/14. https://www.hesa.ac.uk/data-andanalysis/publications/students-2013-14/introduction .

Hoare, A. and Johnston, R. (2011) 'Widening participation through admissions policy - a British case study of school and university performance', Studies in Higher Education, 36: 1, pp. 21-41.

Houghton, A., and Piggott, L. (2008) 'The role of special educational needs co-ordinators in raising disabled students awareness of summer schools in higher education institutions: barriers and bridges' in Widening Participation and Lifelong Learning, 10 (1), pp. 24-33.

Houghton, A., Holland, N. and Armstrong, J. (2016) Widening Participation at Lancaster Medical School, Report for NHS Higher Education North West, REAP-Researching Equity, Access and Participation: Lancaster University. (unpublished)

Houghton, A. and Holland, N. (2016) Who counts?:Exploring the challenges of widening participation data and the changing profile of adults in James, N. (Ed) Adult Education in Austere Times, Conference Proceedings 5-7 July 2016, Vaughan Centre for Lifelong Learning: University of Leicester. https://www2.le.ac.uk/departments/lifelong-learning/events/scutrea/conferenceproceedings-2016

Leman, J. 2015. What Do Taught Postgraduates Want? The Postgraduate Taught Experience Survey 2015. York: Higher Education Academy. https://www.heacademy.ac.uk/system/files/ptes 2015 what do pgts want.pdf.

Lynch, J., Walker-Gibbs, B. and Herbert, S. (2015) 'Moving beyond a 'bums-on-seats' analysis of progress towards widening participation: reflections on the context, design and evaluation of 
an Australian government-funded mentoring programme', Journal of Higher Education Policy and Management, 37:2, pp.144-158.

Mcmanus, I. (2004). Measuring participation in UK medical schools: Social class data are problematic to interpret. BMJ, 329(7469), 800.

MSC. (2014). Selecting for Excellence: Final Report. Medical School Council. http://www.medschools.ac.uk/SiteCollectionDocuments/Selecting-for-Excellence-FinalReport.pdf

NICHE: National Committee of Inquiry into Higher Education, (1997) Higher Education in the learning society. (Dearing Report). Available at: http://www.leeds.ac.uk/educol/ncihe/

Neves, J., and N. Hillman. (2016) The 2016 Student Academic Experience Survey. York: Higher Education Academy. http://www.hepi.ac.uk/wp-content/uploads/2016/06/Student-AcademicExperience-Survey-2016.pdf

OFFA (2016) Outcomes of access agreement monitoring for 2014-15. (May 2016/04) Available at: https://www.offa.org.uk/wp-content/uploads/2016/05/2016.04- Outcomes-of-accessagreements-monitoring-1.pdf

Ofsted: Office for Standards in Education (2016) Ofsted data dashboards decommissioning (15 ${ }^{\text {th }}$ March, 2016) Available at: http://dashboard.ofsted.gov.uk/news.php

ONS: Office for National Statistics (2016) Teaching Excellence Framework: Review of Data Sources Interim Report.

https://www.gov.uk/government/uploads/system/uploads/attachment data/file/5 23291/bis16-269-teaching-excellence-framework-review-of-data-sources- interim-report.pdf

Payne, G. (2013) 'Models of Contemporary Social Class: the Great British Class Survey'. Methodological Innovations Online, 8, 1 pp. 3-17 http://mio.sagepub.com/content/8/1/3.full.pdf Rawson, A. (2016) The Caring University in 2016: Practice, Partnership and Strategy with the Care Experienced Student, Action on Access http://actiononaccess.org/wpcontent/files $\mathrm{mf} /$ thecaringuniversityin201618.pdf

Robertson, D. and Hilman, J. (1997) Widening participation in higher education for students from lower socio-economic groups and students with disabilities. (Report 6 for National Committee of Inquiry into Higher Education). Available at: http://www.leeds.ac.uk/educol/ncihe/

Social Mobility and Child Poverty Commission (2016) Social Mobility Index. Available at: https://www.gov.uk/government/uploads/system/uploads/attachment data/file/4 96103/Social Mobility Index.pdf

Stevenson, J. 2012. Black and Minority Ethnic Student Degree Retention and Attainment. York: Higher Education Academy. https://www.heacademy.ac.uk/system/files/bme summit final report.pdf.

Student Finance England. 2015. Student Finance for Academic Year 2015 to 2016. Accessed 1 June 2015. https://www.gov.uk/studentfinancesteps

UCAS (2016) UCAS Undergraduate reports by sex, area background, and ethnic group, 9th June 2016. Available at https://www.ucas.com/corporate/data-and-analysis/ucas-undergraduatereleases/ucas-undergraduate-reports-sex-area

UUK (2016) Working in partnership: enabling social mobility in higher education - the final report of the Social Mobility Advisory Group (October, 2016). Available at http://www.universitiesuk.ac.uk/policy-and-analysis/reports/Pages/working-in-partnershipenabling-social-mobility-in-higher-education.aspx 
Woodfield, R. (2014) Undergraduate retention and attainment across the disciplines. York: Higher Education Academy. Available at:

https://www.heacademy.ac.uk/sites/default/files/resources/undergraduate retenti on and attainment across the disciplines.pdf

\section{Notes on contributors}

Dr Natalie Holland is Research Associate for REAP (Researching Equity, Access and Participation) based in Lancaster University's Department of Educational Research. Her research interests relevant to this paper include the relationship between quantitative and qualitative use of data across the student life cycle, especially for mature and part-time adult learners.

Dr Ann-Marie Houghton is Director of REAP (Researching Equity, Access and Participation) based in Lancaster University's Department of Educational Research. Her research interests include evaluation of widening access to HE initiatives, with a particular focus on the use of student data to inform inclusive curriculum design and institutional and sector-wide policy developments associated with disability.

Dr Jo Armstrong is Research Associate for REAP (Researching Equity, Access and Participation) based in Lancaster University's Department of Educational Research. Her research includes evalu- ation of widening access issues using an institutional cohort study that includes consideration of intersectionality especially of gender and social class.

Claire Mashiter is Research Associate for REAP (Researching Equity, Access and Participation) based in Lancaster University's Department of Educational Research. Her research interests include evaluation of students' volunteering and paid opportunities to contribute to widening access activities. Her PhD is exploring the social value and social capital of third-sector community groups. 